\title{
A case of successful full-thickness resection using endoscopic submucosal dissection and transanal suturing of rectal cancer
}

Endoscopic resection techniques have been applied to full-thickness resection of gastrointestinal neoplasms as combination procedures with surgical resection [1,2]. However, the applications of these procedures are mainly limited to the upper gastrointestinal tract owing to severe leakage complications in the lower gastrointestinal tract. Here we present a case of a successful full-thickness resection using endoscopic submucosal dissection (ESD) techniques to treat rectal adenocarcinoma $[3,4]$.

A 68-year-old man with a rectal flat elevated lesion, $20 \mathrm{~mm}$ in diameter, was referred to our department ( $\mathbf{F i g . 1} \mathbf{a}$ ). We consulted surgeons for a radical resection because of the estimated depth of invasion. General anesthesia was judged to be risky because of the patient's severe chronic obstructive pulmonary disease. After careful discussion with surgeons, we decided to resect the lesion by using a combination of ESD techniques and transanal suturing ( $\vee$ Video 1 ).

After creating a circumferential mucosal incision around the lesion, two clips were anchored directly to the muscular layer on one side of the lesion. One of the clips was tied with a line to pull from outside the body. Pulling the line, we incised the muscular layer around the lesion ( $\mathbf{F i g . 1} \mathbf{b}$ ). Finally, the lesion was resected in an en bloc fashion that included the muscular layer (\Fig.1c). The muscular defect was completely closed by transanal suturing ( $>$ Fig. 1 d). Computed tomography immediately after the procedure revealed minimal leakage of air into the retroperitoneal space ( $\mathbf{F i g} . \mathbf{2}$ ).

The patient recovered well without any complications. Histopathological assessment revealed that a well-differentiated adenocarcinoma had invaded beneath the muscular layer, with free vertical and lateral margins.
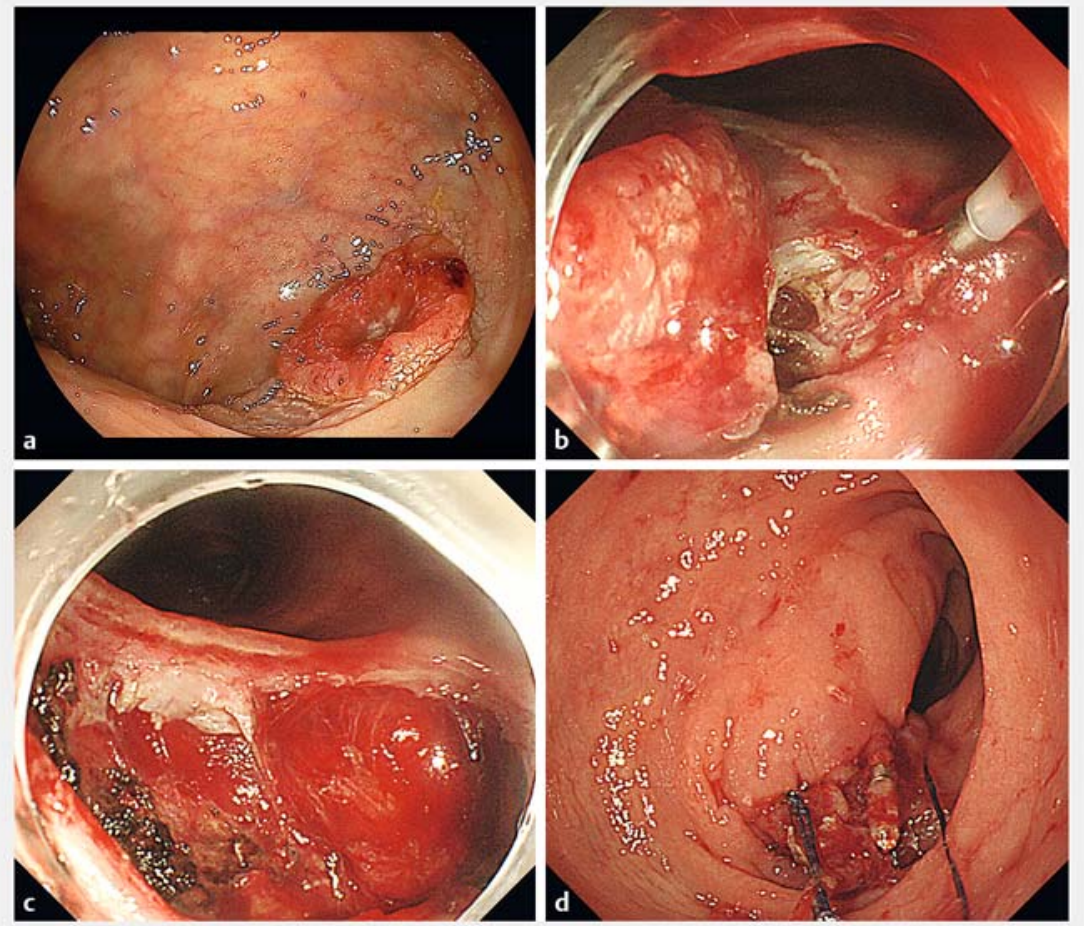

Fig. 1 Full-thickness resection of rectal tumor. a White-light endoscopy image of the rectal tumor. b A small incision was made between the two clips. c The muscular defect after fullthickness resection. $\mathbf{d}$ The muscular defect was sutured completely.
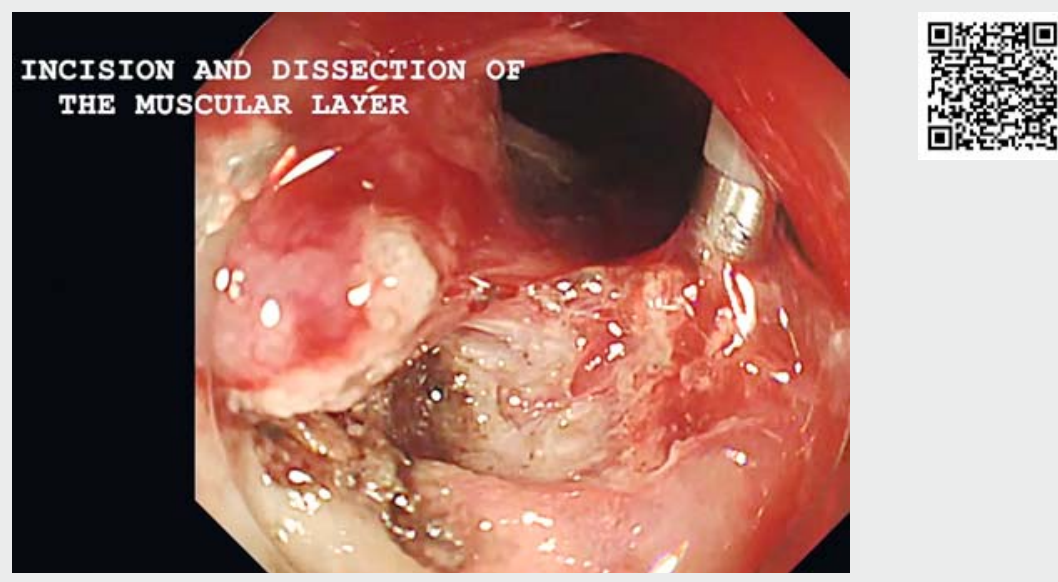

$\checkmark$ Video 1 Procedures of full-thickness resection using endoscopic submucosal dissection and transanal suturing. 


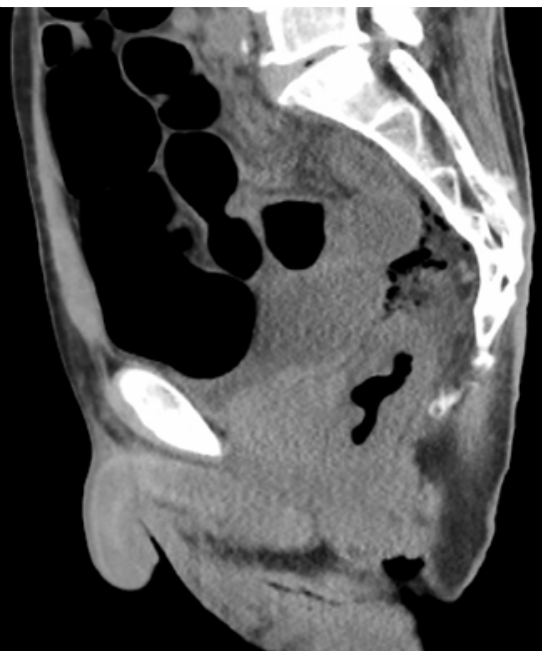

- Fig. 2 Air leakage was limited around the mucosal defect.

Thus, full-thickness resection using ESD techniques may be acceptable for patients at high risk of needing radical resection for lesions located on the retroperitoneal side by completely suturing the muscular defect.

Endoscopy_UCTN_Code_TTT_1AQ_2AD

\section{Competing interests}

None

The authors

Satoshi Ono ${ }^{1}$, Ryosuke Kobayashi $^{2}$, Shun Ito ${ }^{1}$, Shosuke Hosaka', Shin-ichiro Sato ${ }^{1}$, Kiyotaka Umeki ${ }^{1}$, Satoshi Wakasugi ${ }^{1}$

1 Department of Gastroenterology, ChibaNishi General Hospital, Matsudo, Japan

2 Department of Surgery, Chiba-Nishi General Hospital, Matsudo, Japan

\section{Corresponding author}

\section{Satoshi Ono, MD, PhD}

Department of Gastroenterology, ChibaNishi General Hospital, 1-107 Kanegasaku, Matsudo, Chiba 270-2251, Japan

Fax: +81-47-3895162

satoshi-tky@umin.ac.jp

\section{References}

[1] Hiki N, Nunobe S, Matsuda T et al. Laparoscopic endoscopic cooperative surgery. Dig Endosc 2015; 27: $197-204$

[2] Goto O, Takeuchi H, Sasaki M et al. Laparoscopy-assisted endoscopic full-thickness resection of gastric subepithelial tumors using a nonexposure technique. Endoscopy 2016; 48: $1010-1015$
[3] Fujishiro M, Yahagi N, Kakushima $\mathrm{N}$ et al. Outcomes of endoscopic submucosal dissection for colorectal epithelial neoplasms in 200 consecutive cases. Clin Gastroenterol Hepatol 2007; 5: 678-683

[4] Mizutani H, Ono S, Ohki D et al. Recent development of techniques and devices in colorectal endoscopic submucosal dissection. Clin Endosc 2017; 50: 562-568

\section{Bibliography}

DOI https://doi.org/10.1055/a-0915-1847

Published online: 23.5.2019

Endoscopy 2019; 51: E301-E302

(C) Georg Thieme Verlag KG

Stuttgart · New York

ISSN 0013-726X

\section{ENDOSCOPY E-VIDEOS}

https:/|eref.thieme.de/e-videos

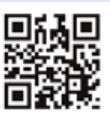

Endoscopy E-Videos is a free access online section, reporting on interesting cases and new

techniques in gastroenterological endoscopy. All papers include a high quality video and all contributions are freely accessible online.

This section has its own submission website at

https://mc.manuscriptcentral.com/e-videos 